\title{
Description of Protosticta binhi sp. n. from the Central Highlands of Vietnam (Odonata: Zygoptera: Platystictidae)
}

\author{
Quoc Toan Phan (D) a*, Van Quang To ${ }^{\mathrm{b}, \mathrm{c}}$, Dang Mau Trinh (1D) ${ }^{\mathrm{d}}$ and Van Khuong Dinh (D) \\ ${ }^{a}$ Center for Entomology \& Parasitology Research, Institute of Research and Training of Medicine, Biology \\ \& Pharmacy, Duy Tan University, Da Nang City, Vietnam; ${ }^{b}$ Department of Zoology, Southern Institute of \\ Ecology, Vietnam Academy of Science and Technology, Ho Chi Minh City, Vietnam; ${ }^{c}$ Graduate University \\ of Science and Technology, Vietnam Academy of Science and Technology, Ha Noi City, Vietnam; ${ }^{d}$ Faculty \\ of Biology and Environmental Science, The University of Education, Danang University, Da Nang City, \\ Vietnam; ${ }^{e}$ Institute of Aquaculture, Nha Trang University, Nha Trang City, Vietnam
}

(Received 20 May 2019; final version received 19 November 2019)

\begin{abstract}
Protosticta binhi sp. n. is described from the Central Highlands of Vietnam (holotype male: Vietnam, Gia Lai Province, K'Bang District, Dak Roong Commune, Dak Hro village, $14.36611^{\circ} \mathrm{N}, 108.4103^{\circ} \mathrm{E}, 1130$ $\mathrm{m}$ asl, 22 May 2018, T.odo. 22051810, Zoological Collection of Duy Tan University). The new species can be easily distinguished from all other Protosticta species by the combination of huge body size, birdhead shape of cerci and paraprocts broad and apically armed with several sharp subapical projections in the male, and the anterior pronotal lobe of the prothorax well developed in the female.
\end{abstract}

http://www.zoobank.org/urn:1sid:zoobank.org:pub:F047FB25-2B21-447D-8E4A-BA3A7DC77138

Keywords: dragonfly; damselfly; new species; Protostictinae

\section{Introduction}

Phan \& Kompier (2016) provided an overview of the genus Protosticta Selys, 1855 in Vietnam with nine recorded species. Later, Kompier (2016) described three new species, P. proboscis Kompier, 2016, P. albifrons Kompier, 2016 and $P$. nigra Kompier, 2016, as well as providing a description of the previously unknown female of $P$. linnae $i$ van Tol, 2008 and including a key to the males of the P. curiosa group of Vietnamese and Thai fauna. Subsequently, P. albifrons was shown to be a junior synonym of $P$. curiosa Fraser, 1934 (Kompier 2018), resulting in a total of 12 species of Protosticta for Vietnam as follows: P. beaumonti Wilson, 1997 (dark form), $P$. caroli van Tol, 2008, P. curiosa, P. grandis (Asahina, 1984), P. linnaei, P. ngoai Phan \& Kompier, 2016, P. nigra, P. proboscis, P. pseudocuriosa Phan \& Kompier, 2016, P. satoi Asahina, 1997, $P$. socculus Phan \& Kompier, 2016 and P. spinosa Phan \& Kompier, 2016. Females of P. ngoai, P. proboscis and $P$. socculus are still unknown.

In this paper, we describe Protosticta binhi sp. n. from the Central Highlands of Vietnam. The combination of the bird-head shape of the cerci and the paraprocts armed with several sharp

*Corresponding author. Email: pqtoan84@gmail.com 
subapical projections for the male, and the anterior pronotal lobe of the prothorax of the female, helps to easily separate Protosticta binhi sp. n. from its congeners.

\section{Materials and methods}

Specimens were collected in the field by hand net, placed in rectangular envelopes and steeped in $100 \%$ acetone for 8-12 hours before drying. Each specimen is preserved dry in a rectangular clear envelope with its data printed on the card backing each specimen.

The habitus of the holotype male and paratype female of the new species were photographed with a Nikon D3300 camera (Nikon factory, Ayuthaya, Bangkok, Thailand) with lens Nikon AFS DX Micro Nikkor 85 mm f/3.5G ED VR (Nikon factory, Ayuthaya, Bangkok, Thailand). Color photos of structures were taken by Axiocam Erc 5s on Zeiss Stemi 508 Stereo Microscope (Carl Zeiss AG, Oberkochen, Germany). Black and white illustrations were rendered using Adobe Photoshop 7.0 (Adobe Systems Incorporated, Mountain View, California, U.S.).

Morphological terminology follows Phan \& Kompier (2016). Abbreviations: S1-10, abdominal segments 1 to 10 ; Px, postnodal crossveins.

\section{Taxonomy}

Family Platystictidae Kennedy, 1920

Subfamily Protostictinae Dijkstra, Kalkman, Dow, Stokvis \& van Tol, 2013

Genus Protosticta Selys, 1855

Protosticta binhi sp. n. Phan, To, Trinh \& Dinh

(Figures 1-15)

\section{Etymology}

The first author chose the specific name "binhi" after the last name of his father, Mr. Phan Dinh Binh (born in 1952) to whom he is grateful for his love and support. A noun in genitive case.

\section{Type specimens}

Holotype $\sigma^{\top}$ : A mature male, T.odo. 22051810, Dak Hro village $\left(14.36611^{\circ} \mathrm{N}, 108.4103^{\circ} \mathrm{E}\right.$, $1130 \mathrm{~m}$ asl), Dak Roong Commune, K'Bang District, Gia Lai Province, 22 May 2018, Q.T. Phan leg.; - Paratypes: $10^{\top}, 2$ o (T.odo. 22051811-13), all mature, same data as holotype.

\section{Type specimen deposition}

All type specimens of the new species are deposited in the Zoological Collection of Duy Tan University, Danang, Vietnam.

\section{Diagnosis}

The bird-head shape of the cerci, the paraprocts longer than the cerci, broad and armed with several sharp subapical projections of the male are unique amongst Protosticta species; anterior pronotal lobe of prothorax of the female extends up and backward much further than in the known Protosticta females. 


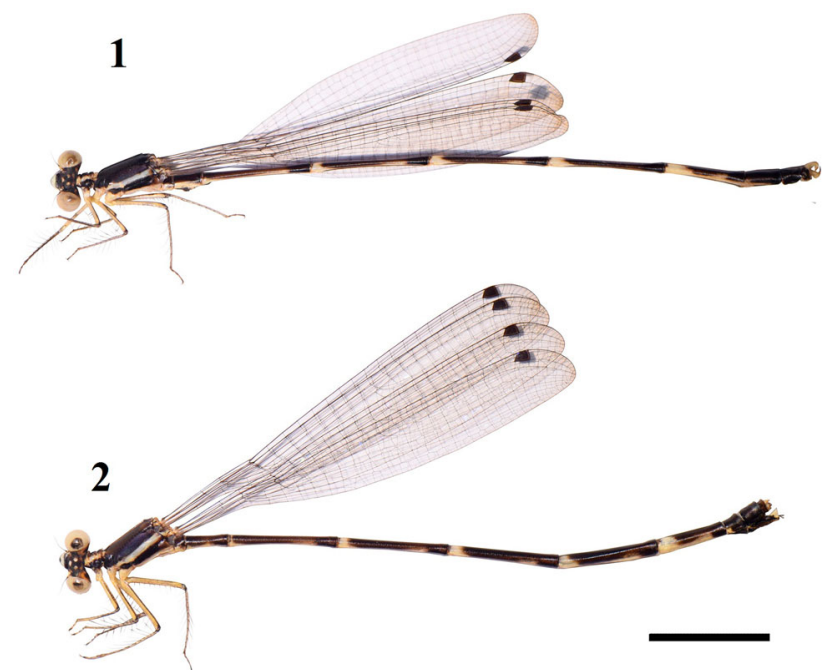

Figures 1,2. Habitus of (1) holotype $\sigma^{7}$ and (2) paratype $q$ of Protosticta binhi sp. n.
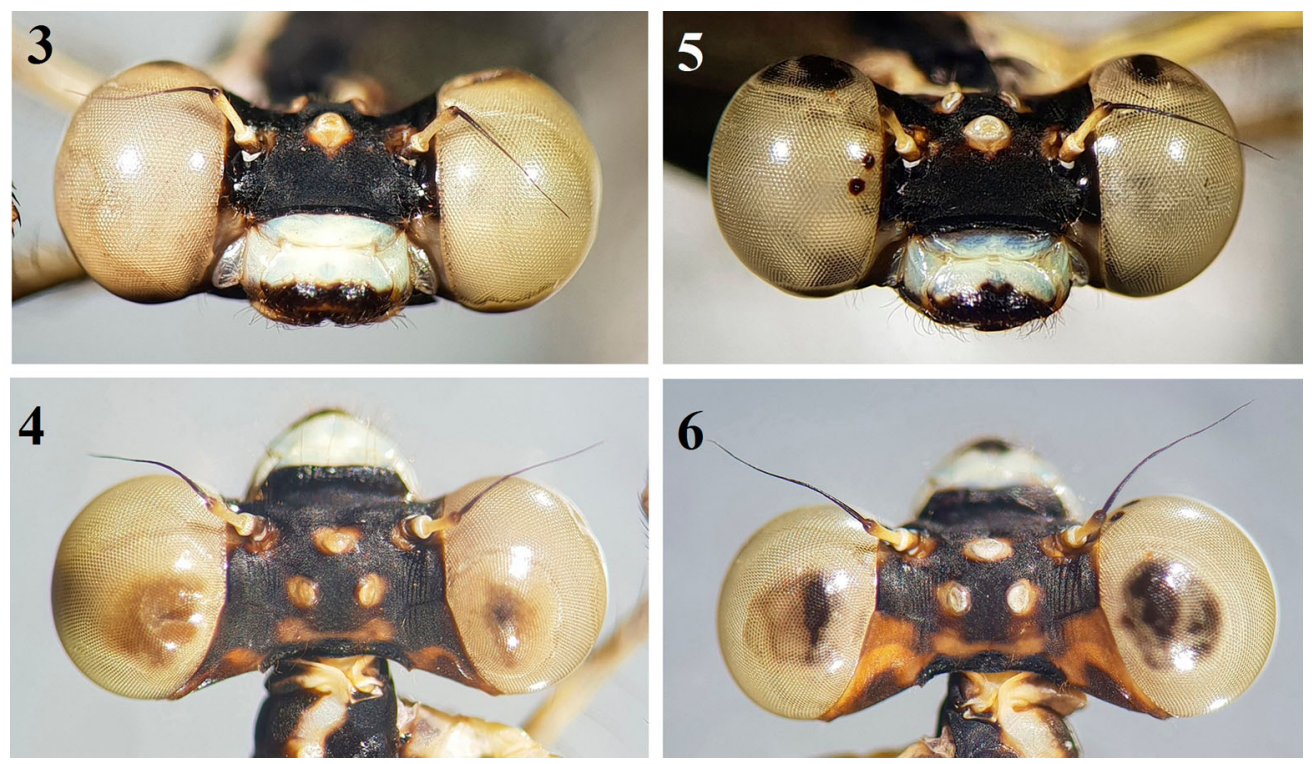

Figures 3-6. Head of holotype $\sigma^{7}$ and paratype $q$ of Protosticta binhi sp. n. $(3,5)$ in frontal view; $(4,6)$ in dorsal view.

\section{Description of holotype male}

Head (Figures 3, 4). Labium pale yellow, tip with movable hooks black. Labrum, anteclypeus, postclypeus, mandibles and genae whitish, lower margin of labrum shining black. Frons matte black. Base of antennae black, the second segment brown, the third one yellow with a black apical ring, remaining segments entirely black. All ocelli surrounded by yellow. Epicranium matte black with a dark yellow occipital bar and two post-ocular spots. Occipital ridge black, either end with a small but distinct sharp spine. 

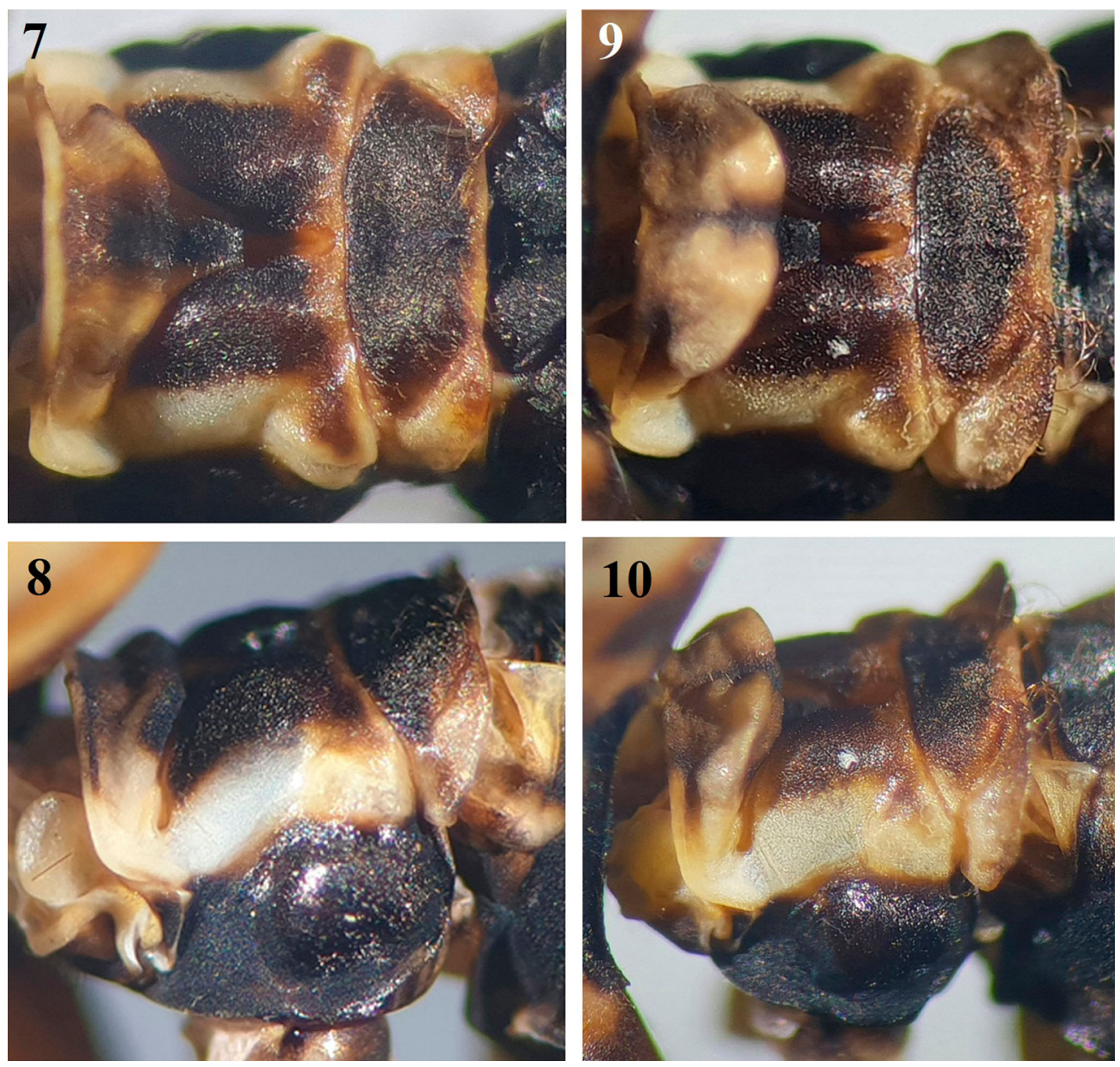

Figures 7-10. Structure of prothorax of holotype $\sigma^{7}$ and paratype $q$ of Protosticta binhi sp. n. $(7,9)$ in dorsal view; $(8,10)$ in oblique-dorsal view.

Thorax. Prothoracic pronotum as in Figures 7, 8. Anterior pronotal lobe slightly prominent in lateral view; posterior pronotal lobe dorsally black, posterior margin and two raised hind lobes yellowish. Lateral margin of all three lobes whitish, this forming a straight white line in lateral view (Figures 7, 10). Propleuron black. Synthorax black except for a large white mesepimeral stripe and another pale yellowish stripe on lower margin of metepimeron (Figure 1).

Legs. Coxae yellow, base of prothoracic legs with a brownish spot; trochanter yellow; femur yellow speckled with black in its flexor surface; tibia dark yellow, flexor surface black; tarsus yellow; claws and armature black.

Wings hyaline, light brown at apex. Px 17 in fore wing and 18 in hind wing. Pterostigma brownish.

Abdomen (Figure 1). Dorsal half of S1-2 black, the remainder pale yellow; S3 brown on top, pale yellow below, posterior 1/5th black; S4-6 black, pale ventral color extending upward to form an annulus anteriorly; S7 with basal third whitish, this stripe narrower than that of preceding 

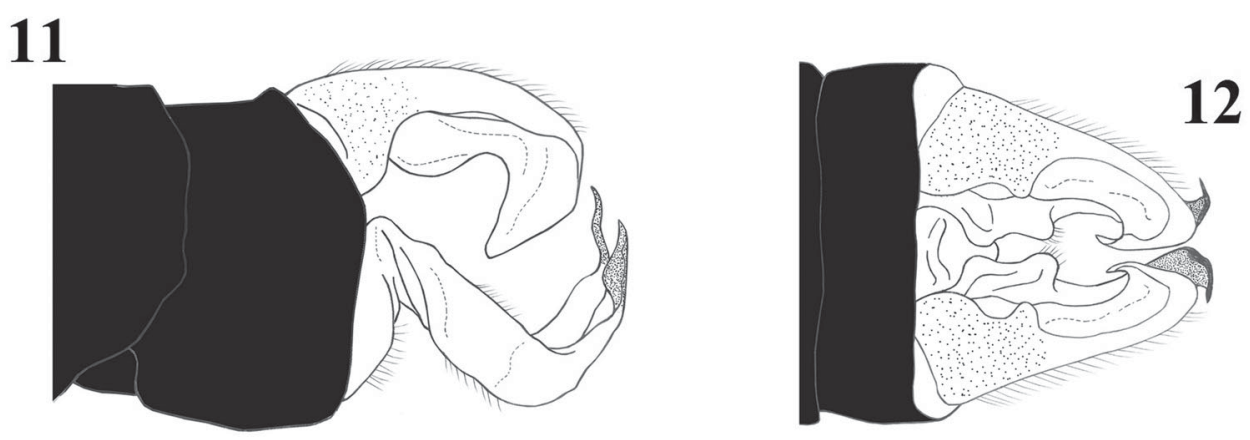

\section{3}
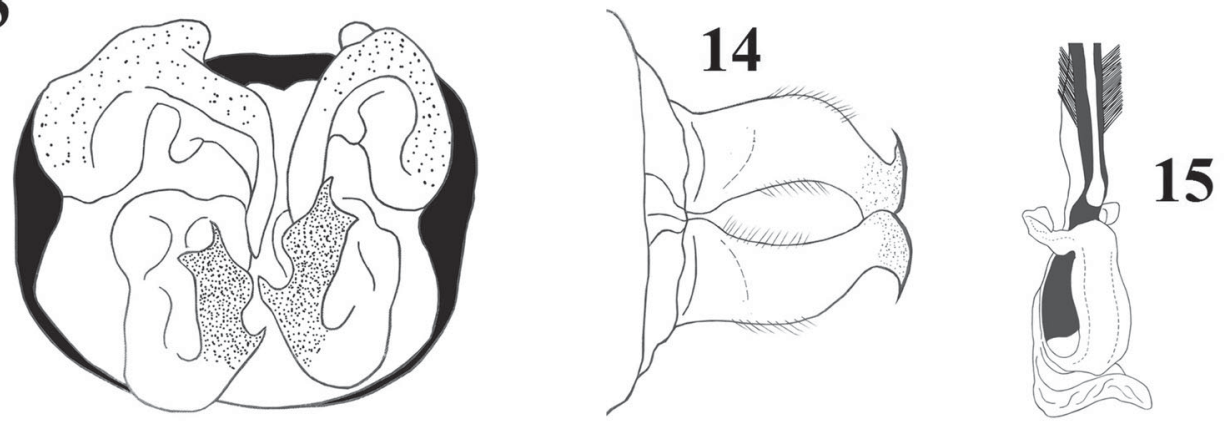

Figures 11-15. Protosticta binhi sp. n., structurally features of holotype $\sigma^{x},(11)$ appendages in lateral view; (12) appendages in dorsal view; (13) appendages in posterodorsal view; (14) paraprocts in ventral view; (15) genital ligula.

segments, slightly broader posteriorly; S8 black except for a thin stripe connecting with whitish marking on S7; S9-10 entirely black.

Genital ligula as in Figure 15, the tip with two short apical flagella each curved distally.

Anal appendages (Figures 11-14) whitish with tip of paraprocts brown. Cerci shorter than paraprocts, strongly curved, pointed distally, shaped in the form of a bird's head (Figure 11). In lateral view, paraprocts $\mathrm{N}$-shaped, posterior part narrower with tip strongly curved upward (Figure 11); in posteroventral view, paraprocts broad, inflated apically with sharp spines laterally (Figure 13).

Measurements (in mm). Hind wing 33; abdomen (including appendages) 54.

\section{Description of paratype female}

Color pattern as in holotype male, except for the following differences: Back of the head almost completely yellow with some dark smudges, two semicircular postocular streak broadly extending and touching two spots behind lateral ocelli (Figure 6). Anterior pronotal lobe of prothorax much more prominent than that of male (Figure 10). Wings with 15 Px in hind wing. S8 lacking a stripe but with yellow confined to ventrobasal portion of segment (Figure 2). Cerci, stylus and tip of ovipositor pale yellow, remainder black. 
Variation in paratype male and female

Paratype specimens show no significant differences from the holotype male and the female paratype used for description.

\section{Habitat and ecology}

The new species was found in a shaded shallow narrow (about 1-3 m width) forest mountain stream with slow running water, with a sandy bottom with many large rocks in Dak Hro village (1130 $\mathrm{m}$ asl).

\section{Differential diagnosis}

Among the genus Protosticta Selys, 1855, the new species and P. robusta Fraser, 1933, P. grandis, P. taipokauensis Asahina \& Dudgeon, 1987 and P. ngoai share a similar robust body size, black synthorax with two distinct yellow/whitish stripes and pale yellow/white labrum and appendages (the labrum of the holotype P. ngoai was described as black (Phan \& Kompier 2016),
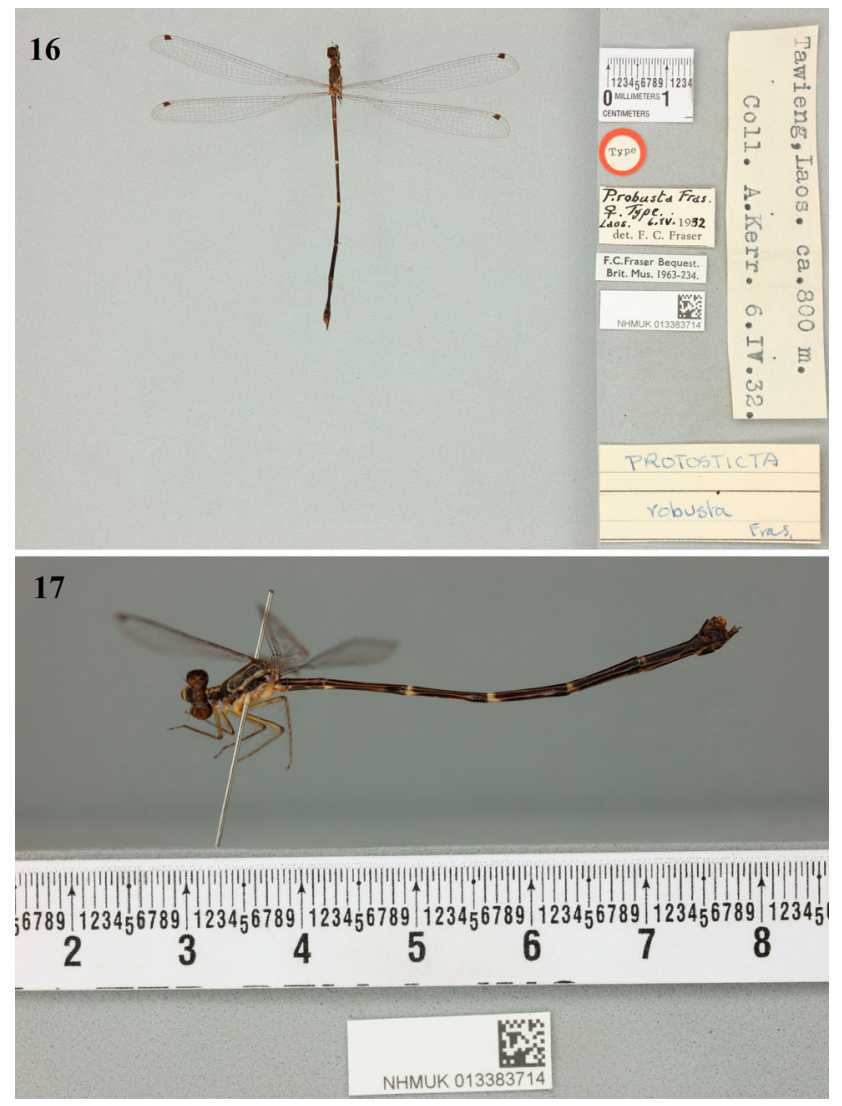

Figures 16,17. Protosticta robusta, holotype female in (16) dorsal view and (17) lateral view. Photographed by Dr Ben Price in the Natural History Museum, London. 

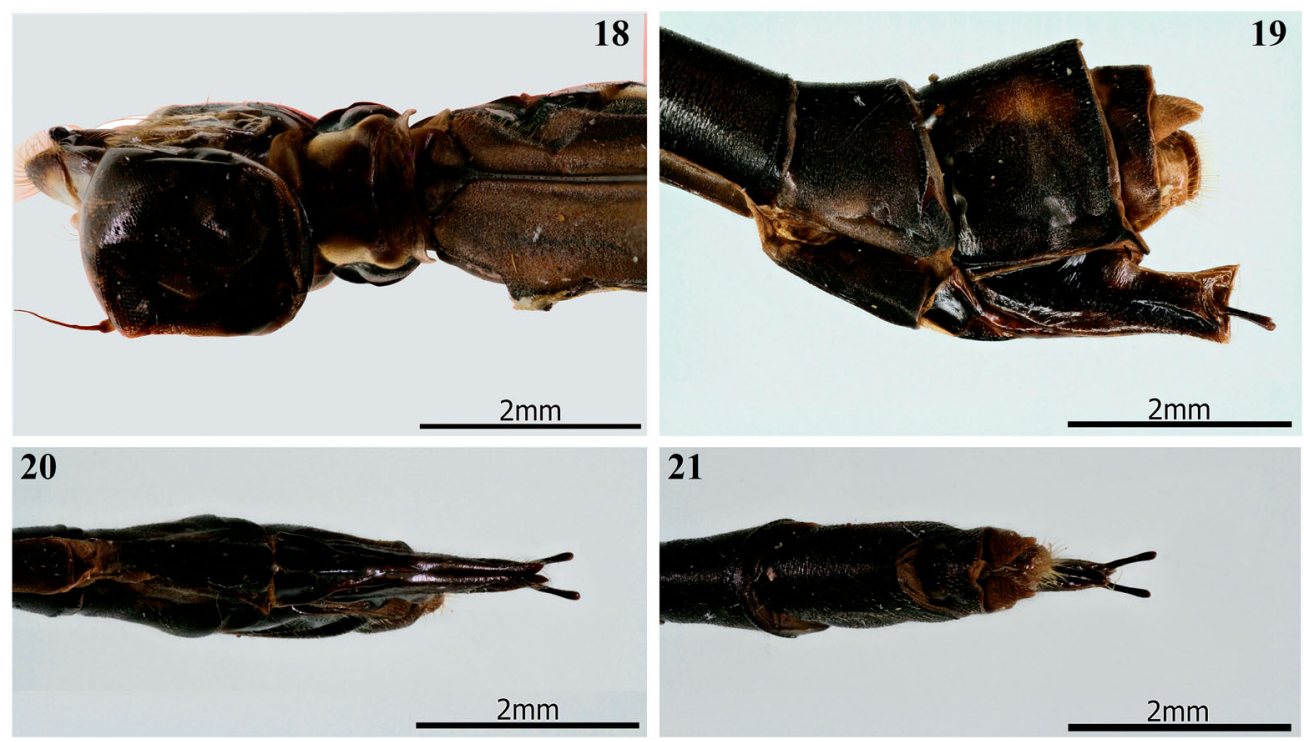

Figures 18-21. Protosticta robusta, structural features of holotype female: (18) prothorax in dorsal view; abdominal tip in (19) lateral view, (20) ventral view and (21) dorsal view. Photographed by Dr Ben Price at the Natural History Museum, London.

but based on our subsequent observation this appears to be an aberration). The male of Protosticta binhi differs from P. grandis, P. ngoai and P. taipokauensis (note that P. robusta is only known from a single female) by the following characters: cerci shaped like a bird's head, paraprocts longer than cerci, broad and armed with some sharp subapical projections (Figures 11-13) whereas these are roundly apically, shorter or pointed apically but lacking subapical projections in P. grandis, P. ngoai and P. taipokauensis (figures 3B, 4C, 4I in Phan \& Kompier 2016). The anterior pronotal lobe of the female prothorax of $P$. binhi sp. $\mathrm{n}$. is distinctive, elongated upwards and backwards (Figure 10), but lacks such elongation in the holotype female of P. robusta (Figure 18) as well as in P. grandis (figure $3 \mathrm{G}$ in Phan \& Kompier 2016) and P. taipokauensis (figure 4 in Asahina \& Dudgeon 1987).

\section{Discussion}

Protosticta robusta Fraser, 1933, characterized by its high numbers of postnodal crossveins in both wings (22 in forewings and 20 in hind wings) (Figure 16), was described from Laos based on a single female (Fraser 1933). The high numbers of crossveins in forewings of the holotype specimen of $P$. robusta is considered unique with $P$. grandis, $P$. ngoai and $P$. taipokauensis having just 16-19 Px, but Kompier (pers. comm.) collected a male of $P$. ngoai sensu Phan \& Kompier from Tam Dao National Park, northern Vietnam with 21 Px in both wings and some specimens of $P$. grandis sensu Asahina from Bach Ma National Park and Lam Dong Province, all central Vietnam, with 20 Px. This indicates there is considerable variation in the number of postnodal crossveins in these species, one of which may well be conspecific with P. robusta.

According to Phan and Kompier (2016), the male of Protosticta grandis in Vietnam is easily separated from P. ngoai and P. taipokauensis by its broad cercal tips (figures 3B, 4C in Phan \& Kompier 2016). P. grandis or $P$. ngoai or even $P$. taipokauensis may be a junior synonym of the $P$. robusta, given that they were all described without knowledge of the variability of Px amongst this group and no other differential characters were established to separate these species from 
P. robusta (Asahina, 1984; Asahina \& Dudgeon 1987; Phan \& Kompier 2016). Indeed, we could verify no reliable characters by which to differentiate the holotype female of $P$. robusta (Figures 16-21) from the examined specimens of $P$. grandis sensu Asahina from Vietnam (see Phan \& Kompier 2016) and P. ngoai sensu Phan \& Kompier from Vietnam (see Phan \& Kompier 2016) and Laos (1 $\sigma^{x}, 2$, Vang Vieng, Laos, 19 April 2002; $1 \sigma^{x}, 1$ \%, Oudomxay, Laos, 2 May 2009; $2 \sigma^{7}$, Lak Sao, Laos, 20 May 2016, all collected by Naoto Yokoi) in this study. As mentioned above, it will require further study to settle the taxonomic status of $P$. grandis, $P$. ngoai and P. taipokauensis. That would require, apart from the study (including molecular analysis) of a wide geographical range of additional material, the examination of the type specimens of grandis and taipokauensis. Settling this issue is further hampered by the fact that the male of P. robusta is still unknown. Collecting at the type locality in Laos of specimens would be highly beneficial to settle the taxonomic relationships between P. robusta, P. grandis, P. ngoai and P. taipokauensis in the future.

\section{Acknowledgements}

We are grateful to Mr Tom Kompier, Dr Rosser Garrison and Dr Keith Wilson for revising and improving the first draft (and in the case of Mr Tom Kompier and Dr Keith Wilson subsequent drafts) of this manuscript; Mr Naoto Yokoi for his help with the examination of the specimens from Laos; Dr Ben Price in the Natural History Museum, London providing photos of the type specimen of P. robusta; the IDEAL WILD Foundation for supporting the first author with the Micro Nikkor lens; Dr Le Nguyen Bao, provost of Duy Tan University for supporting the first author with fieldwork and Mr Pham Nhat Tan for his arrangement of the necessary permits for survey in Kon Ka Kinh National Park.

\section{Funding}

We are grateful to the International Dragonfly Fund and Nagao Natural Foundation for their financial support to conduct the field trip in Kon Ka Kinh National Park. This research is mainly funded by the Vietnam National Foundation for Science and Technology Development (NAFOSTED) under grant number106.05-2018.351.

\section{ORCID}

Quoc Toan Phan (D) http://orcid.org/0000-0002-3154-6546

Dang Mau Trinh (D) http://orcid.org/0000-0002-3662-2392

Van Khuong Dinh (D) http://orcid.org/0000-0003-0766-9148

\section{References}

Asahina, S. (1984). A list of the Odonata from Thailand. Part III. Platystictidae. Kontŷu, 52, 585-595.

Asahina, S., \& Dudgeon, D. (1987). A new platystictid damselfly from Hong Kong. Tombo, 30(1/4), 2-6.

Kompier, T. (2016). New species of Protosticta Selys from Vietnam with a key to the males of the P. curiosa group. (Odonata: Platystictidae). Zootaxa, 4193(2), 347-360. doi:10.11646/zootaxa.4193.2.9

Kompier, T. (2018). Protosticta curiosa Fraser, 1934 and its synonyms in Vietnam and China (Odonata: Platystictidae). Zootaxa, 4434(2), 373-376. doi:10.11646/zootaxa.4434.2.8

Fraser, F. C. (1933). Dragonflies from the Laos country. Journal of the Siam Society, Natural History Supplement, 9 , $109-141$

Phan, Q. T., \& Kompier, T. (2016). A study of the genus Protosticta Selys, 1855, with descriptions of four new species from Vietnam (Odonata: Platystictidae). Zootaxa, 4098(3), 529-544. doi:10.11646/zootaxa.4098.3.6

van Tol, J. (2008). Notes on some species of the genus Protosticta from Vietnam (Odonata, Platystictidae). Zoologische Mededelingen Leiden, 82, 217-234. 